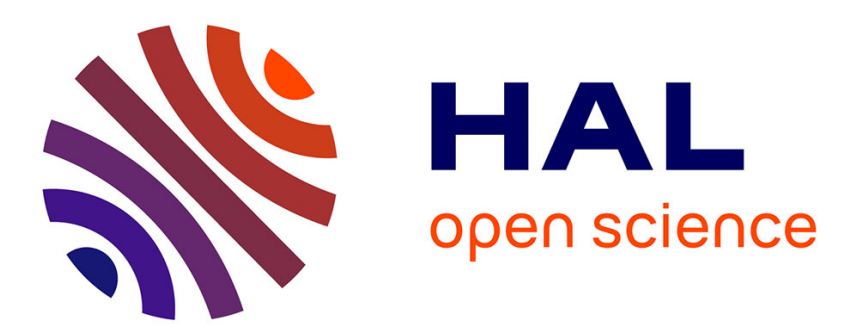

\title{
The hydraulic reaction of tricalcium silicate observed by microwave dielectric measurements
}

\author{
J.-P. Reboul
}

\section{To cite this version:}

J.-P. Reboul. The hydraulic reaction of tricalcium silicate observed by microwave dielectric measurements. Revue de Physique Appliquée, 1978, 13 (8), pp.383-386. 10.1051/rphysap:01978001308038300 . jpa-00244464

\section{HAL Id: jpa-00244464 https://hal.science/jpa-00244464}

Submitted on 1 Jan 1978

HAL is a multi-disciplinary open access archive for the deposit and dissemination of scientific research documents, whether they are published or not. The documents may come from teaching and research institutions in France or abroad, or from public or private research centers.
L'archive ouverte pluridisciplinaire HAL, est destinée au dépôt et à la diffusion de documents scientifiques de niveau recherche, publiés ou non, émanant des établissements d'enseignement et de recherche français ou étrangers, des laboratoires publics ou privés. 


\title{
REVUE DE PHYSIQUE APPLIQUÉE
}

\author{
Classification \\ Physics Abstracts \\ $07.50-33.20 \mathrm{~B}-68.45-77.40$
}

\section{THE HYDRAULIC REACTION OF TRICALCIUM SILICATE OBSERVED BY MICROWAVE DIELECTRIC MEASUREMENTS}

\author{
J.-P. REBOUL \\ Laboratoire d'Electricité, Université des Sciences et Techniques du Languedoc, \\ place Eugène-Bataillon, 34060 Montpellier Cedex, France
}

(Reçu le 30 janvier 1978, révisé le 2I arril 1978. acrepté le 8 mai 1978)

\begin{abstract}
Résumé. - La réaction hydraulique du silicate tricalcique a été suivie sur des pâtes fraîches par des mesures diélectriques en microondes, pendant les trente premières heures. Les variations des propriétés diélectriques permettent de distinguer trois phases dans la réaction, qui pourraient correspondre à trois mécanismes successifs.
\end{abstract}

\begin{abstract}
The hydraulic reaction of tricalcium silicate has been observed on fresh pastes by microwave dielectric measurements, for the first 30 hours. The changes of the dielectric behaviour lead to discriminate three phases of the reaction which might correspond to three succeeding mechanisms.
\end{abstract}

1. Introduction. - Various physical methods have already been used to investigate the succeeding mechanisms involved in the portland cement hydratation. The principal ones are based on ultrasound velocity measurements [1], electron microscopy [2]. infrared spectrometry [3] and hertzian spectroscopy [4]. In spite of such an host of performing techniques, the various hydratation mechanisms of portland cement are not yet, by several details, perfectly known, chiefly in the earlier moment of the paste. So, after we set up a microwave dielectric method [5] using a cavity resonator as a tool to determine moisture content of powders and porous solids and as a mean to discriminate combined water from moisture inside a fresh cement paste, we tried to bring our collaboration in confirming some hydrating processes in pastes of tricalcium silicate. This material, whose chemical formula is $\mathrm{Ca}_{3} \mathrm{SiO}_{5}$ and usual abreviation $\mathrm{C}_{3} \mathrm{~S}$ is one of the principal portland cement component but the pure product is very valuable because it requires a long and difficult synthesizing way to be obtained. Our microwave method which needs small material quantities is then particularly convenient for such a precious product and this paper is concerned with the results of our work on this material.

2. Microwave apparatus and technique. - The hydratation of a fresh cement paste, that is principally the change into hydratation water of a large part of the moisture content of the paste may be followed by a microwave dielectric testing. Indeed, in the microwave range, the dielectric losses of moisture and free water are much larger than the losses of the hydrates to be formed. Thus, the hydratation is accompanied by a decrease of the dielectric losses. However the various methods available for measuring the complex permittivity of solid or liquid materials in the microwave range are not well suited to high-dielectric-loss materials such a fresh cement paste. Now, we have set up a new method which is described in other works $[5,6]$ and consisting in determining, at $3000 \mathrm{MHz}$, the normalized microwave admittance $Y / Y_{0}$ of small cylindrical samples introduced in a length-adjustable parallelipipedic cavity resonator. This method is particularly convenient for liquids, powders and pastes because it allows the use, as samples, of glass or plastic tubes filled with the material to be tested. Besides each testing may be brief since it requires only gathering two parameters : the new resonant length of the sample-loaded cavity and the length sweep for a $3 \mathrm{~dB}$ attenuation of resonance. These are obtained by adjusting and reading the micrometric screw of the cavity.

When the measurements are not to be done at room temperature, that is, when the sample and the measuring cavity resonator are to remain in a thermal enclosure, turning and reading the cavity micrometric screw become uneasy. So, it may be more convenient to operate differently. Instead of adjusting the cavity length, and keeping the frequency unvaried. it is 
more easy to adjust the oscillator frequency, and to keep the cavity length unvaried. This new testing process is as brief as the preceding. In each test, the two parameters to be collected are now the new resonant frequency of the sample-loaded cavity and the frequency sweep for a $3 \mathrm{~dB}$ attenuation of resonance. These are obtained, out of the thermal enclosure, by adjusting and reading the frequency dial of the oscillator.

The connection between the length parameters of the first measuring way and the frequency parameters of the second may be deduced by derivating the formula :

$$
f=\frac{c}{2}\left(\frac{1}{l^{2}}+\frac{1}{b^{2}}\right)^{1 / 2}
$$

$f$ : frequency,

$l$ : cavity length,

$b$ : larger side of the rectangular section of the cavity resonator,

$c$ : light velocity.

The connection between frequency and length may also be experimentally settled by previously calibrating the frequency dial of the oscillator as a function of the corresponding cavity resonator length. Thus, following this second procedure instead of the first one does not change the basis of the method.

From the measurement data (length or frequency) the sample admittance may be deduced. Then from the admittance data, the material complex permittivity of the material may be computed [6].

But for the present purpose which is more setting up and dating the structure or composition changes in the cement paste than appointing the transient material permittivity, the long and approximate computation which leads to the material permittivity from the sample admittance is not necessary. The changes in the sample admittance are as significant as the changes in the material permittivity.

Indeed an increase of the dielectric loss of the material leads to an increase of the imaginary part $\varepsilon^{\prime \prime}$ of its complex permittivity $\varepsilon^{\prime}-j \varepsilon^{\prime \prime}$ but it leads to an increase of the real part $G$ (or dissipative term) of the normalized admittance $G+j B$ of the sample. So $\varepsilon^{\prime \prime}$ and $G$, which else are complexly connected, are both increasing functions of dielectric losses.

So in the present study which is essentially. qualitative, tracing the changes of the sample admittance was quite sufficient. According to these considerations and from measuring the microwave admittance of $\mathrm{C}_{3} \mathrm{~S}$ samples [7] while setting, we could divide the first 30 hours of fresh paste into three principal periods or phases corresponding probably to three succeeding hydratation mechanisms in the bulk of the tempered material.

3. The first period or adsorption phase. - The first period in the dielectric behaviour of the paste overlaps a time interval of about one hour after the tempering. During this period of time, the admittances of the samples, at room temperature, remain unvaried which means the complete moisture content of the paste does not change and consequently the hydrates are not yet being formed from the moisture of the paste. But the change of free water into adsorbed water, if any, is not detected since at room temperature free and adsorbed water have the same high dielectric loss. In the microwave range to discriminate free water from adsorbed water, the measurements are to be done at a temperature below $0{ }^{\circ} \mathrm{C}$ where only the dielectric loss of free water vanishes. All this suggested us the following experiment :

Several identical samples (sealed tubes) numbered 1 , $2,3 \ldots$ are prepared from the same fresh paste. At the time $t_{1}$, measured from the tempering as time origin, the sample 1 is plunged into an alcohol bath at $-20{ }^{\circ} \mathrm{C}$ inside a freezer in order to be cooled rapidly. At the time $t_{2}$ the sample 2 is also plunged in the bath, and so on. Later, the admittances of the frozen samples are measured at $-20^{\circ} \mathrm{C}$ with the cavity resonator previously placed in the freezer.

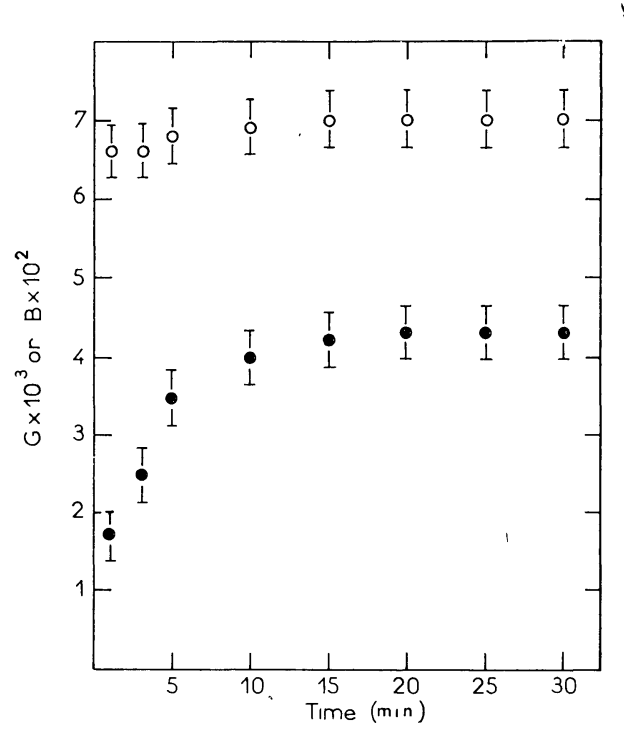

FIG. 1. - Real part $G(\bullet)$ and imaginary part $B(0)$ of the normalized admittance, at $-20^{\circ} \mathrm{C}$, of 8 samples of the same $\mathrm{C}_{3} \mathrm{~S}$ paste as a function of time before cooling. Water $/$ silicate $=0.5$; sample diameter $=4 \mathrm{~mm}$; frequency $\simeq 3000 \mathrm{MHz}$.

The results of such measurements are shown by the figure 1 , where the admittances of the sample 1, 2, $3 \ldots$ are plotted as functions of the time intervals $t_{1}, t_{2}, t_{3} \ldots$ respectively. It appears that the sample admittances depend on the time interval between tempering and cooling, that is the life of the paste at room temperature. On the contrary after cooling and while the sample is frozen, we could observe that the admittance was remaining unvaried. So the sample admittance may be measured at any time, if left at $-20^{\circ} \mathrm{C}$.

The preceding experiment shows that the latter cooled samples are the more dissipative ones. Thus 
the adsorbed water content is larger in the latter cooled samples than in the former. We may then think there is a non-instantaneous adsorption phenomenon which is stopped when the paste is cooled at $-20^{\circ} \mathrm{C}$. So the adsorbed water content is smaller in the former cooled samples. From our results we may say that in the studied $\mathrm{C}_{3} \mathrm{~S}$ pastes there is an adsorption phenomenon overlapping, for the least, the time interval between 2 minutes and 10 minutes after the tempering.

After 10 minutes this phenomenon progressively vanishes and becomes negligible and before 2 minutes our method is inoperative. Indeed preparing a sample requires about 1 minute and the time needed to freeze the sample is also about 1 minute (an identical water-filled glass tube plunged in the alcohol bath requires 45 seconds to be completely frozen).

4. The second period or dissolution phase. - During the first hour, as we have said, the admittance of the samples at room-temperature remains unvaried. But after one hour we observe a slight increase of the reál part of the admittance which means the paste become slightly more conductive (Fig. 2). This increase is slight but sufficient to be detected; besides it has been observed on all the tested samples. So we may say that the period of the paste from one hour to five hours

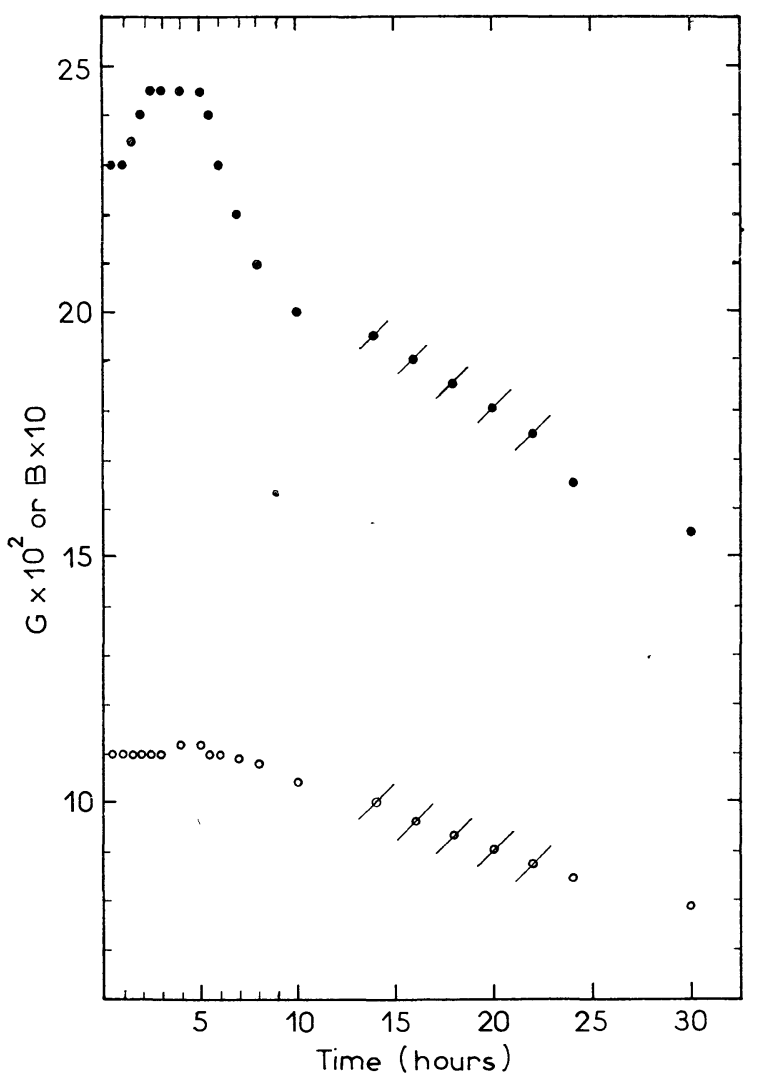

FIG. 2. - Real part $G(\bullet)$ and imaginary part $B(O)$ of the normalized admittance, at $+20^{\circ} \mathrm{C}$, of a sample of $\mathrm{C}_{3} \mathrm{~S}$ paste as a function of time measured from tempering. Water/silicate $=0.35$; sample diameter $=4 \mathrm{~mm}$; frequency $=3000 \mathrm{MHz}$. Crossed points are from a second sample. corresponds to a maximum of conduction or dielectric loss in the microwave range.

The interpretation is not easy, for many other specific physical and chemical behaviours have been found for this period. For example, concerning the emitted heat flow measured by Sierra [8], it is to be noted that this period is just overlapping the increasing part of the heat flow curve. Nowadays two kinds of mechanisms are kept as possible to explain the hydrate forming process. Some authors [9-10] hold the hydrates to be formed from anhydrous $\mathrm{C}_{3} \mathrm{~S}$ by a direct water fixing process. The others [11-12], according to Le Chatelier's hypothesis, hold the hydrates to be formed from the satured solution after a first $\mathrm{C}_{3} \mathrm{~S}$ dissolution phase. From our results we may think that the slight increase of the conductive properties of the paste is due to the increase of the number of ions in the solution, so we feel inclined in favour of the second mechanism and we have called this period the dissolution phase.

Recently Barret et al. [13] measured an increase of the lime concentration in the solution for the first five hours following mixing anhydrous $\mathrm{C}_{3} \mathrm{~S}$ in water. Such a result agrees with our assumption of the increase of the number of ions. But this school of investigators and particularly one of them [14], discussing the two possible mechanisms mentionned above, showed the first mechanism may lead to the same lime concentration as the second, so the increase of the lime concentration is not to be taken into account for choosing one of the two mechanisms. However the assumption of the first mechanism involves two phenomena amenable to microwave dielectric measurements : the increase of the number of ions in the solution (which leads usually to a slight increase of the dielectric loss) and the decrease of the paste moisture content changed into combined water (which leads usually to a large decrease of the dielectric loss); so we may think that the all qualitative result should be a decrease of the dielectric loss which is not what is observed. On the contrary, in the assumption of the second mechanism, one phenomenon only is amenable to microwave dielectric measurement : the increase of the number of ions which leads usually to a slight increase of the dielectric loss and which is what is observed. So we feel again inclined in favour of the second mechanism. Consequently this dissolution phenomenon, if any, would occur after the first period, that is after the adsorption phase. It may be then supposed that the material dissolving requires a previous water adsorption which would delay the dissolution phase.

5. The third period or crystallization phase. - After 5 or 6 hours, the conductive properties of the paste being at their maximum value, the dielectric losses of the paste begin to decrease steeply. This decrease is steep untill the 20th hour and then progressively vanishes, but no discontinuities are to be found on the admit- 
tance variation curve during this period (Fig. 2). In fact, the real part of the normalized admittance of the sample seems to decrease according to an exponential law as the discharge of a capacitor. This period which can easily be detected by our method because the variations of the dielectric losses are very noticeable, corresponds to the change into crystallization water of a great part of the moisture content of the paste. Indeed as we have already said. in the microwave range and at room temperature, the dielectric losses are large in moisture and negligible in crystallization water. So the changing of moisture into crystallization water is accompanied by a large decrease of the dielectric losses of the paste. Because of the formation of hydrates and crystallization water the period from the 6th to 30th hour was designated by us as the crystallization phase.

After the 30th hour, the hydrate formation is probably going on but our study was carried on no longer.

6. Conclusion. - We have tried to bring the contribution of a new microwave method for investigating and confirming the various mechanisms of the $\mathrm{C}_{3} \mathrm{~S}$ hydraulic reaction from the earlier moment of the paste. From the obtained results, it appears that some hydrating processes are amenable to dielectric microwave testing and, in particular, three principal water reaction types in the bulk of the paste seem to be responsible for the observed changes in the dielectric behaviour. But many other processes involved in the $\mathrm{C}_{3} \mathrm{~S}$ hydraulic reaction may have passed unnoticed. So, adding and comparing the presently observed microwave behaviour to the results from other investigating techniques will make the complete hydraulic reaction of $\mathrm{C}_{3} \mathrm{~S}$ better known and understood.

Acknowledgments. - The author wishes to thank the "Centre d'Etudes et de Recherches de l'Industrie des Liants Hydrauliques » (C.E.R.I.L.H.) and particularly Mrs Regourd, Head of the Microstructure Department for suggesting this study and for graciously furnishing the necessary quantities of $\mathrm{C}_{3} \mathrm{~S}$ powder.

\section{References}

[1] Raoult, F., Le Bot, J., Baron, A., Rev. Mater. Constr. 698 (1976) 37.

[2] Regourd, M., Hornain, H., Rev. Mater. Constr. 693 (1975) 73.

[3] Baron, A., Sierra, R., Rev. GaMS, Methodes Phys. Anal. 4 (1968) 412

[4] Le Bot, J. J., C. R. Hebd. Séan. Acad. Sci. 255 (1962) 2247.

[5] Reboul, J. P., C. R. Hebd. Séan. Acad. Sci. 282B (1976) 393.

[6] R'eboul, J. P., Analusis 48 (1976) 373.

[7] Tricalcium silicate powder furnished by the C.E.R.I.L.H. Granulometry between 20 and $40 \mu \mathrm{m}$.

[8] Sierra, R.. Thesis, Rennes (1974).
[9] Kondo, R., Ueda, S., Proc. Int. Symp. Chem. Cem. 5th, Tokyo, 1968.

[10] Fierens, P., Verhaegen, J. P., Cem. Concr. Res. 5 (1975) 587.

[11] Greenberg, S. A., Chang, T. N., J. Phys. Chem. 692 (1965) 553.

[12] Regourd, M., Hormain, H., Mortureux, B., Rev. Mater. Constr. 693 (1975) 87.

[13] Barret, P., Menetrier, D., Bertrandie, D., Rev. Int. Hautes Temp. Réfract. 14 (1977) 127.

[14] Menetrier, D., Thesis, Dijon (1977). 